\title{
Polyurethanes as self-healing materials
}

\author{
Tomasz Szmechtyk*, Natalia Sienkiewicz, Joanna Woźniak, Krzysztof Strzelec
}

Institute of Polymer and Dye Technology, Lodz University of Technology, Stefanowskiego St. 12/16, 90-924 Lodz, Poland

\begin{tabular}{l}
\hline C H R O N I C L E \\
\hline Article history: \\
Received October 21, 2014 \\
Received in revised form \\
January 29, 2015 \\
Accepted 8 March 2015 \\
Available online \\
8 March 2015 \\
\hline Keywords: \\
Polyurethanes \\
Self-healing \\
Microcontainers \\
Reversible Polymer \\
Microvascular Network \\
\hline
\end{tabular}

A B S T R A C T
The current development of polyurethane self-healing materials has been evaluated and
reviewed. Three main ways of self-healing - microcontainers, microvascular networks and
reversible polymers - are described, and recent most prominent examples of self-healing
materials applications presented.

The current development of polyurethane self-healing materials has been evaluated and reversible polymers - are described, and recent most prominent examples of self-healing materials applications presented.

\section{Introduction}

Polyurethanes (PUR) are probably the most versatile group of currently known plastics. They exhibit very wide range of density, hardness and stiffness, what allows to obtain various types of PUR stretchable fibers, stiff elastomers, flexible and rigid lightweight foams. PUR materials are extensively applied as coatings, adhesives, furniture, textile fibers, artificial leather, etc. ${ }^{1}$

Self-healing is process of healing invisible microcracks aimed at extending safety and working life of polymeric materials. The idea of self-healing appeared in $1980^{2}$ and since then three main repairing solutions have been invented. First generation self-healing system has been based on microcapsules with liquid healing agent (endo-dicyclopentadiene) and solid phase Grubbs-type catalyst, both embedded in polymer matrix ${ }^{3}$. In this method repairing in the same area could not be repeated due to exhaustion of healing agent. This limitation was solved by application of intrinsic microvascular network instead of microcapsules ${ }^{4}$. The third self-healing solution - reversible polymers - also allows to mend cracks multiple times via thermal treatment ${ }^{5}$.

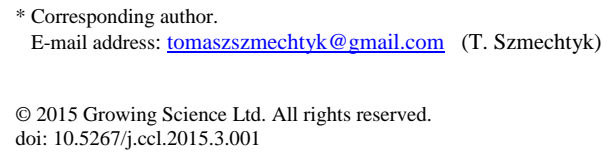




\section{Microcontainers}

Microcontainers, like microcapsules and hollow fibers, are small particles, which comprise healing agent. Practically the only type of microcontainers applied specially in PUR matrix are microcapsules and they are generally used in paints and coatings. In first studies gelatin and urea-formaldehyde were used as two different shell materials, but problem with their stability was observed due to interaction with paint solvents ${ }^{6}$.

Recent works offer effective self-healing systems with linseed oil as healing agent ${ }^{7,8}$. Jadhav et al. ${ }^{7}$ created microcapsules with shell made from phenol-formaldehyde resin and core containing drier and corrosion inhibitor along the mentioned above oil. They noticed that roughness or toughness of shell surface provides better compatibility with polymer matrix ${ }^{7}$. Tatiya et al. created polyurea microcapsules made from polyamidoamine dendrimer of zero generation. They focused on obtaining microcontainers, which show great thermal stability up to $380^{\circ} \mathrm{C}$ with high self-healing effectiveness ${ }^{8}$. Promising results of these two studies could be impulse for further research.

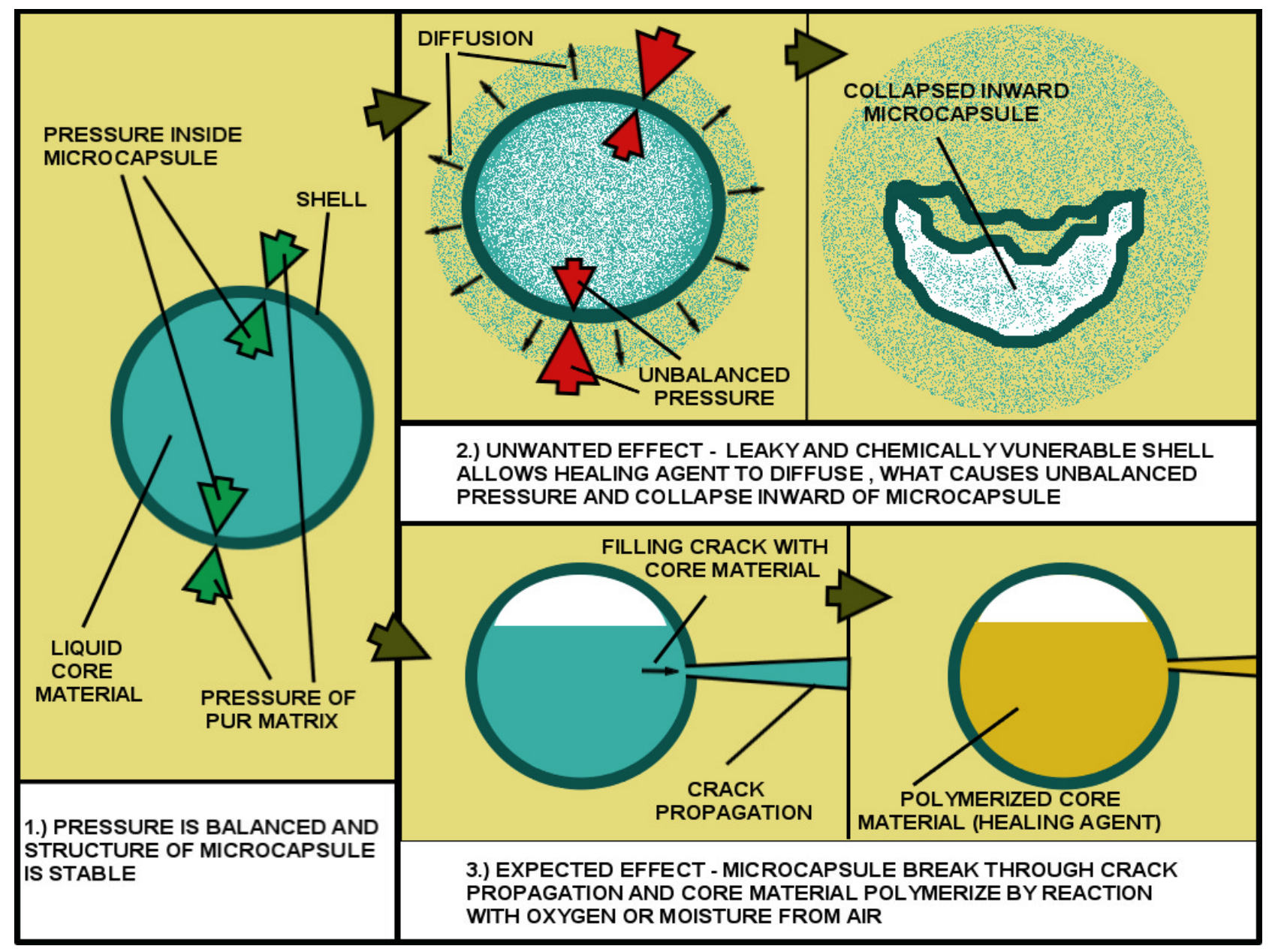

Scheme 1. The possible ways of microcapsule damage, which lead to controlled release of healing agent and polymerization or unwanted diffusion and microcapsule collapse.

In contrast to the small number of articles, which describe usage of microcontainers especially in PUR matrix, there are a lot of works presenting PUR as shell material for capsules embedded in another polymer matrixes. Yang et al. ${ }^{9}$ proposed in 2008 self-healing system, where reactive isophorone diisocyanate (IPDI) is a catalyst-free healing agent. IPDI was successfully imprisoned in PUR shell via interfacial polymerization. Following studies yielded variations of the system, like double walled PUR/poly(urea-formaldehyde) microcapsules with improved mechanical strength and thermal stability (up to $\left.180^{\circ} \mathrm{C}\right)^{10}$. Another solutions were poly(urea-urethane) nanoparticles synthesized by self- 
assembled neutralization emulsification ${ }^{11}$ and PUR microcapsules filled with water-borne PUR paint 12 .

\section{Microvascular 3D Networks}

Microvascular network mimics cardiovascular system. Analogously to it, in this self-healing system, crack area could be repaired repeatedly by healing agent, which is transported via microvascular 3D network embedded in the polymer matrix ${ }^{4}$. According to review written by Wu et al. ${ }^{13}$ and latest reports, it can be concluded, that there is no papers describing usage of intrinsic microvascular 3D network concretely in PUR. However, there is probably no objections to use in PU microvascular networks, which are not assigned to specific polymer. Examples of possibly useful new systems are woven glass ${ }^{14}$ and reinforced with halloysite nanotubes ${ }^{15}$ microvascular networks, both presented by White and co-workers.

\section{Reversible Polymers}

Reversible polymer is a polymeric material, which can heal itself multiple times under different types of radiation, originally heat. Healing mechanism involves energy from radiation to form bonds at the interface of the mended parts. This is possible due to the presence of reversible reactions, particularly the Diels-AIder reaction ${ }^{5}$.

Current studies provide reversible mending in PUR via different ways. Ghosh and Urban created PUR networks, which exhibit self-repairing ability upon exposure to ultraviolet light. In this network an oxetane-substituted chitosan precursor is incorporated into a two-component PUR. When mechanical damage occurs, two reactive ends create through opening each four-member oxetane rings. Exposure to UV light causes scission of chitosan chain, which crosslinks with the reactive oxetane ends, thus repairing the network ${ }^{16}$. Alternative photo-stimulated self-healing PUR contains dihydroxyl coumarin derivatives, which are able to undergo photocleavage and photodimerization under UV light ${ }^{17}$.

González-García et al. presented another type of reversible polymer - shape memory PUR (SMPUR). SMPUR is block co-polymer, which is constituted of PUR segments as hard domains and poly-( $\varepsilon$-caprolactone) (PCL) as the soft domains. Although SMPUR mends via thermal treatment, self-healing mechanism is not based on Diels-Alder reactions. Due to fact, that PUR has melting temperature at $173{ }^{\circ} \mathrm{C}$ and PCL only at $52{ }^{\circ} \mathrm{C}$, increasing temperature between the melting points of the domains physical self-healing is observed. Self-healing is based on relaxation of PCL matrix and consequent capability of filling damaged area. PUR segments are meanwhile responsible for maintaining mechanical properties ${ }^{18}$. Further research focused on investigation of the self-healing properties showed that SMPUR with $12 \%$ of hard domains has the ability to self-repair ${ }^{19}$.

As one of the latest reversible polymers, Huang et al. reported thermoplastic PUR with few-layer graphene (FG-TPUR). Presence of graphene provides enhanced mechanical properties with the ability to multichannel and repeatable self-healing. High mechanical strength comes from good compatibility between graphene and polymeric materials. Moreover, graphene shows outstanding thermal and electrical conductivity with good microwave and infrared (IR) absorbing capacity. This allows to heal FG-TPUR by three different methods: via IR light, electromagnetic wave or electricity ${ }^{20}$. Concurrently, reversible polymers based on Diels-Alder reactions are still examined and provide new self-healing materials like polyether-maleimide-based $\mathrm{PUR}^{21}$. 


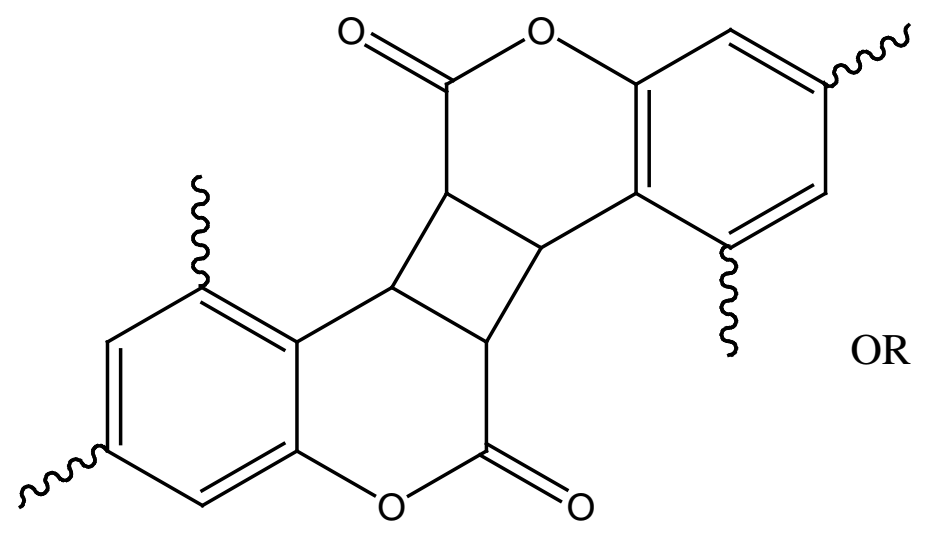<smiles>[R]Sc1cc(N)cc2c1C1C(C(=O)O2)C2C(=O)Oc3cc(S)cc([Y9])c3C21</smiles><smiles>O=c1ccc2c(S)cc(I)cc2o1</smiles><smiles>O=c1ccc2c(S)cc(I)cc2o1</smiles>

Scheme 2. Self-healing mechanism utilizing [2+2] cycloaddition of coumarin fragments in PUR chains

\section{Conclusions}

In summary, three types of self-healing have been described in relation to their presence of PUR. Data shows that most popular in PUR materials self-healing system are reversible polymers, in contrast to hollow fibers and microvascular networks, which are practically not used. Attractiveness of reversible polymers is probably resultant of their repeatability, relatively uncomplicated process of preparing and possible maintenance of mechanical properties. Although, the collected data analysis leads to a conclusion, that application of self-healing systems based on PUR is not very common. This is probably caused by PUR versatility, what in many cases makes preparation of self-healing PUR technically difficult and therefore unprofitable. 


\section{Acknowledgement}

The authors would like to thank the anonymous referees for constructive comments on earlier version of this paper.

\section{References}

1. Sarier N., Onder E. (2007) Thermal characteristics of polyurethane foams incorporated with phase change materials. Thermochimica Acta, 454, 90-98.

2. Jud K., Kausch H.H., Williams J.G. (1981) Fracture-mechanics studies of crack healing and welding of polymers. J. Mater. Sci., 16, 204-210.

3. White S.R., Sottos N.R., Moore J., Geubelle P., Kessler M., Brown E., Suresh S., Viswanathan S., (2001) Autonomic healing of polymer composites. Nature, 409, 794-797.

4. Toohey K.S., Sottos N.R., Lewis J.A., Moore J.S., White S.R. (2007) Self-healing materials with microvascular networks. Nat. Mater., 6 , 581 .

5. Chen X.X., Dam M.A., Ono K., Mal A., Shen H.B., Nutt S.R., Sheran K., Wudl F. (2002) A thermally re-mendable cross-linked polymeric material. Science, 295, 1698.

6. Kumar A., Stephenson L.D., Murray J.N. (2006) Self-healing coatings for steel. Progress in Organic Coatings, 55, 244-253.

7. Jadhav R.S., Mane V., Bagle A.V., Hundiwale D.G., Mahulikar P.P., Waghoo G. (2013) Synthesis of multicore phenol formaldehyde microcapsules and their application in polyurethane paint formulation for self-healing anticorrosive coating. International Journal of Industrial Chemistry, 4, 31.

8. Tatiya P.D., Hedaoo R.K., Mahulikar P.P., Gite V.V. (2013) Novel Polyurea Microcapsules Using Dendritic Functional Monomer: Synthesis, Characterization, and Its Use in Self-healing and Anticorrosive Polyurethane Coatings. Eng. Chem. Res., 52, 1562-1570.

9. Yang J., Keller M.W., Moore J.S., White S.R., Sottos N.R. (2008) Microencapsulation of Isocyanates for Self-Healing Polymers. Macromolecules, 41, 9650-9655.

10. Caruso M.M., Blaiszik B.J., Jin H., Schelkopf S.R., Stradley D.S., Sottos N.R., White S.R., Moore J.S. (2010) Robust, Double-Walled Microcapsules for Self-Healing Polymeric Materials. Appl. Mater. Interfaces, 2 (4), 1195-1199.

11. Cheong I.W., Kim J.H. (2004) Synthesis of core-shell polyurethane-urea nanoparticles containing 4,4'-methylenedi-p-phenyl diisocyanate and isophorone diisocyanate by self-assembled neutralization emulsification. Chem. Commun., 2484-2485.

12. Koh E., Kim N.-K., Shin J., Kim Y.-W. (2014) Polyurethane microcapsules for self-healing paint coatings. RSC Adv., 4, 16214.

13. Wu D.Y., Meure S., Solomon D. (2008). Self-Healing Polymeric Materials: A Review of Recent Development. Prog. Polym. Sci., 5, 479-552.

14. Coppola A.M., Thakre P.R., Sottos N.R., White S.R. (2013) Tensile properties and damage evolution in vascular 3D woven glass/epoxy composite. Composites: Part A, 59, 9-17.

15. Olugebefola S.C., Hamilton A.R., Fairfield D.J., Sottos N.R., White S.R. (2014) Structural reinforcement of microvascular networks using electrostatic layer-by-layer assembly with halloysite nanotubes. Soft Matter, 10, 544

16. Ghosh B., Urban M.W. (2009) Self-Repairing Oxetane-Substituted Chitosan Polyurethane Networks. Science, 323, 1458-1460.

17. Ling J., Rong M.Z., Zhang M.Q. (2012) Photo-stimulated self-healing polyurethane containing dihydroxyl coumarin derivatives. Polymer, 53, 2691-2698.

18. González-García Y., Mol J.M.C., Muselle T., De Graeve I., Van Assche G. (2011) A combined mechanical, microscopic and local electrochemical evaluation of self-healing properties of shapememory polyurethane coatings. Electrochimica Acta, 56, 9619- 9626.

19. Jorcin J.-B., Scheltjens G., Van Ingelgem Y., Tourwé E., Van Assche G., De Graeve I., Van Mele B., Terryn H., Hubin A. (2010) Investigation of the self-healing properties of shape memory 
polyurethane coatings with the 'odd random phase multisine' electrochemical impedance spectroscopy. Electrochimica Acta, 55, 6195-6203

20. Huang L., Yi N., Wu Y., Zhang Y., Zhang Q., Huang Y., Ma Y., Chen Y. (2013) Multichannel and Repeatable Self-Healing of Mechanical Enhanced Graphene-Thermoplastic Polyurethane Composites. Adv. Mater., 25, 2224-2228.

21. Zhong Y., Wang X., Zheng Z., Du P. (2015) Polyether-maleimide-based crosslinked self-healing polyurethane with Diels-Alder bonds. J. Appl. Polym. Sci., 41944. 